\title{
Hybrid extragradient method for generalized mixed equilibrium problems and fixed point problems in Hilbert space
}

\author{
Suhong Li ${ }^{1,2^{*}}$, Lihua $\mathrm{Li}^{1}$, Lijun Cao ${ }^{1}$, Xiujuan $\mathrm{He}^{3}$ and Xiaoyun Yue
}

\section{"Correspondence:}

lisuhong103@126.com

${ }^{1}$ College of Mathematics and Information Technology, Hebei

Normal University of Science and

Technology, Qinhuangdao, 066004,

China

${ }^{2}$ Institute of Mathematics and

Systems Science, Hebei Normal

University of Science and

Technology, Qinhuangdao, 066004

China

Full list of author information is

available at the end of the article

\begin{abstract}
In this paper, we introduce iterative schemes based on the extragradient method for finding a common element of the set of solutions of a generalized mixed equilibrium problem and the set of fixed points of a nonexpansive mapping, and the set of solutions of a variational inequality problem for inverse strongly monotone mapping. We obtain some strong convergence theorems for the sequences generated by these processes in Hilbert spaces. The results in this paper generalize, extend and unify some well-known convergence theorems in literature.
\end{abstract}

MSC: 47H09; 47J05; 47J20; 47J25

Keywords: generalized mixed equilibrium problem; extragradient method; nonexpansive mapping; variational inequality; strong convergence theorem

\section{Introduction}

Let $H$ be a real Hilbert space with the inner product $\langle\cdot, \cdot\rangle$ and the norm $\|\cdot\|$, and let $C$ be a nonempty closed convex subset of $H$. Let $B: C \rightarrow H$ be a nonlinear mapping and let $\varphi: C \rightarrow R \cup\{+\infty\}$ be a function and $F$ be a bifunction from $C \times C$ to $R$, where $R$ is the set of real numbers. Peng and Yao [1] considered the following generalized mixed equilibrium problem:

$$
\text { Finding } x \in C \text { such that } F(x, y)+\varphi(y)+\langle B x, y-x\rangle \geq \varphi(x) \text {. }
$$

The set of solutions of (1.1) is denoted by $\operatorname{GMEP}(F, \varphi, B)$. It is easy to see that $x$ is a solution of problem (1.1) implying that $x \in \operatorname{dom} \varphi=\{x \in C: \varphi(x)<+\infty\}$.

If $B=0$, then the generalized mixed equilibrium problem (1.1) becomes the following mixed equilibrium problem:

Finding $x \in C$ such that $F(x, y)+\varphi(y) \geq \varphi(x)$.

Problem (1.2) was studied by Ceng and Yao [2] and Peng and Yao [3, 4]. The set of solutions of (1.2) is denoted by $\operatorname{MEP}(F, \varphi)$.

If $\varphi=0$, then the generalized mixed equilibrium problem (1.1) becomes the following generalized equilibrium problem:

Finding $x \in C$ such that $F(x, y)+\langle B x, y-x\rangle \geq 0$.

๑) 2013 Li et al.; licensee Springer. This is an Open Access article distributed under the terms of the Creative Commons Attribution License (http://creativecommons.org/licenses/by/2.0), which permits unrestricted use, distribution, and reproduction in any medium, provided the original work is properly cited. 
Problem (1.3) was studied by Takahashi and Takahashi [5]. The set of solutions of (1.3) is denoted by $\operatorname{GEP}(F, B)$.

If $\varphi=0$ and $B=0$, then the generalized mixed equilibrium problem (1.1) becomes the following equilibrium problem:

Finding $x \in C$ such that $F(x, y) \geq 0$.

The set of solutions of (1.4) is denoted by $E P(F)$.

If $F(x, y)=0$ for all $x, y \in C$, the generalized mixed equilibrium problem (1.1) becomes the following generalized variational inequality problem:

Finding $x \in C$ such that $\varphi(y)+\langle B x, y-x\rangle \geq \varphi(x)$.

The set of solutions of (1.5) is denoted by $\operatorname{GVI}(C, \varphi, B)$.

If $\varphi=0$ and $F(x, y)=0$ for all $x, y \in C$, the generalized mixed equilibrium problem (1.1) becomes the following variational inequality problem:

Finding $x \in C$ such that $\langle B x, y-x\rangle \geq 0$.

The set of solutions of (1.6) is denoted by $\operatorname{VI}(C, B)$.

If $B=0$ and $F(x, y)=0$ for all $x, y \in C$, the generalized mixed equilibrium problem (1.1) becomes the following minimization problem:

Finding $x \in C$ such that $\varphi(y) \geq \varphi(x)$.

Problem (1.1) is very general in the sense that it includes, as special cases, optimization problems, variational inequalities, minimax problems, Nash equilibrium problems in noncooperative games and others, see for instance, [1-7].

For solving the variational inequality problem in the finite-dimensional Euclidean spaces, in 1976, Korpelevich [8] introduced the following so-called extragradient method:

$$
\left\{\begin{array}{l}
x_{1}=x \in C, \\
y_{n}=P_{C}\left(x_{n}-\lambda B x_{n}\right), \\
x_{n+1}=P_{C}\left(x_{n}-\lambda B y_{n}\right)
\end{array}\right.
$$

for every $n=0,1,2, \ldots, \lambda \in\left(0, \frac{1}{k}\right)$, where $C$ is a closed convex subset of $R^{n}, B: C \rightarrow R^{n}$ is a monotone and $k$-Lipschitz continuous mapping, and $P_{C}$ is the metric projection of $R^{n}$ into $C$. She showed that if $V I(C, B)$ is nonempty, then the sequences $\left\{x_{n}\right\}$ and $\left\{y_{n}\right\}$, generated by (1.8), converge to the same point $x \in V I(C, A)$. The idea of the extragradient iterative process introduced by Korpelevich was successfully generalized and extended not only in Euclidean but also in Hilbert and Banach spaces, see, e.g., the recent papers of He et at. [9], Gárciga Otero and Iuzem [10], Solodov and Svaiter [11], Solodov [12]. Moreover, Zeng and Yao [13] and Nadezhkina and Takahashi [14] introduced some iterative processes based on the extragradient method for finding the common element of the set of fixed points of nonexpansive mappings and the set of solutions of a variational inequality problem for a monotone, Lipschitz continuous mapping. Yao and Yao [15] introduced 
an iterative process based on the extragradient method for finding the common element of the set of fixed points of nonexpansive mappings and the set of solutions of a variational inequality problem for a $k$-inverse strongly monotone mapping. Plubtieng and Punpaeng [16] introduced an iterative process, based on the extragradient method, for finding the common element of the set of fixed points of nonexpansive mappings, the set of solutions of an equilibrium problem and the set of solutions of a variational inequality problem for $\alpha$-inverse strongly monotone mappings.

In 2003, Takahashi and Toyoda [17], introduced the following iterative scheme:

$$
x_{n+1}=\alpha_{n} x_{n}+\left(1-\alpha_{n}\right) S P_{C}\left(x_{n}-\lambda_{n} T x_{n}\right),
$$

where $\left\{\alpha_{n}\right\}$ is a sequence in $(0,1)$, and $\left\{\lambda_{n}\right\}$ is a sequence in $(0,2 \alpha)$. They proved that if $F(S) \cap V I(A) \neq \emptyset$, then the sequence $\left\{x_{n}\right\}$ generated by (1.9) converges weakly to some $z \in F(S) \cap V I(A)$. Recently, Zeng and Yao [18] introduced the following iterative scheme:

$$
\left\{\begin{array}{l}
x_{0}=x \in C, \\
y_{n}=P_{C}\left(x_{n}-\lambda_{n} x_{n}\right), \\
x_{n+1}=\alpha_{n} x_{0}+\left(1-\alpha_{n}\right) S P_{C}\left(x_{n}-\lambda_{n} A y_{n}\right),
\end{array}\right.
$$

where $\left\{\lambda_{n}\right\}$ and $\left\{\alpha_{n}\right\}$ satisfy the following conditions: (i) $\lambda_{n} k \subset(0,1-\delta)$ for some $\delta \in(0,1)$ and (ii) $\alpha_{n} \subset(0,1), \sum_{n=1}^{\infty} \alpha_{n}=\infty, \lim _{n \rightarrow \infty} \alpha_{n}=0$. They proved that the sequence $\left\{x_{n}\right\}$ and $\left\{y_{n}\right\}$ generated by $(1.10)$ converges strongly to the same point $P_{F(S) \cap V I(C, A)} x_{0}$ provided that $\lim _{n \rightarrow \infty}\left\|x_{n+1}-x_{n}\right\|=0$.

In 2006, Nadezhkina and Takahashi [19] also considered the extragradient method (1.9) for finding a common element of a fixed point of nonexpansive mapping and a set of solutions of variational inequalities, but the convergence result was still the weak convergence. The question posed by Takahashi and Toyoda [17] on whether the strong convergence result can be proved by the same iteration scheme Algorithm (1.9) remains open.

In 2010, with the techniques adopted by Noor and Rassias [20], Huang, Noor and AlSaid [21] set the projected residual function by

$$
R_{\lambda}(x)=x-P_{C}(x-\lambda A x)
$$

it is well known that $x \in C$ is a solution of variational inequality (1.6) if and only if $x \in C$ is a zero of the projected residual function (1.11). They proved the strong convergence result of the iteration scheme (1.9) using the error analysis technique.

In this paper, inspired and motivated by the above researches and Huang, Noor and Al-Said [21], we introduce a new iterative scheme based on the extragradient method for finding a common element of the set of solutions of a generalized mixed equilibrium problem, the set of fixed points of nonexpansive mappings and the set of solutions of an inverse strongly monotone mapping, as follows:

$$
\left\{\begin{array}{l}
x_{1}=x \in C, \\
F\left(u_{n}, y\right)+\left\langle B x_{n}, y-u_{n}\right\rangle+\varphi(y)-\varphi\left(u_{n}\right)+\frac{1}{r_{n}}\left\langle y-u_{n}, u_{n}-x_{n}\right\rangle \geq 0, \quad \forall y \in C, \\
y_{n}=P_{C}\left(u_{n}-\lambda_{n} A u_{n}\right), \\
x_{n+1}=\alpha_{n} x_{n}+\left(1-\alpha_{n}\right) S\left[\beta_{n} x_{n}+\left(1-\beta_{n}\right) P_{C}\left(y_{n}-\lambda_{n} A y_{n}\right)\right],
\end{array}\right.
$$


where $\left\{\alpha_{n}\right\},\left\{\beta_{n}\right\},\left\{r_{n}\right\},\left\{\lambda_{n}\right\}$ satisfy some parameters controlling conditions. We will obtain some strong convergence theorems using the error analysis technique as in [21]. The results in this paper generalize, extend and unify some well-known convergence theorems in the literature.

\section{Preliminaries}

Let $C$ be a closed convex subset of a Hilbert space $H$ for every point $x \in H$. There exists a unique nearest point in $C$, denoted by $P_{C} x$, such that

$$
\left\|x-P_{C} x\right\| \leq\|x-y\| \quad \text { for all } y \in C
$$

$P_{C}$ is called the metric projection of $H$ onto $C$. It is well known that $P_{C}$ is a nonexpansive mapping of $H$ onto $C$ and satisfies

$$
\left\langle x-y, P_{C} x-P_{C} y\right\rangle \geq\left\|P_{C} x-P_{C} y\right\|^{2}
$$

for every $x, y \in H$. Moreover, $P_{C} x$ is characterized by the following properties: $P_{C} x \in C$ and

$$
\begin{aligned}
& \left\langle x-P_{C} x, y-P_{C} y\right\rangle \leq 0, \\
& \|x-y\|^{2} \geq\left\|x-P_{C} x\right\|^{2}+\left\|y-P_{C} x\right\|^{2}
\end{aligned}
$$

for all $x \in H, y \in C$.

A mapping $A$ of $\mathrm{C}$ into $H$ is called monotone if

$$
\langle A x-A y, x-y\rangle \geq 0
$$

for all $x, y \in C$. A mapping $A$ of $C$ into $H$ is called inverse strongly monotone with a modulus $\alpha$ (in short, $\alpha$-inverse strongly monotone) if there exists a positive real number $\alpha$ such that

$$
\langle x-y, A x-A y\rangle \geq \alpha\|A x-A y\|^{2}
$$

for all $x, y \in C$.

Recall that a mapping $S$ of $C$ into itself is nonexpansive if

$$
\|S x-S y\| \leq\|x-y\| \quad \text { for all } x, y \in C .
$$

A mapping $T$ of $C$ into itself is pseudocontractive if

$$
\langle T x-T y, x-y\rangle \leq\|x-y\|^{2}
$$

for all $x, y \in C$. Obviously, the class of pseudocontractive mappings is more general than the class of nonexpansive mappings.

Let $A$ be a monotone mapping from $C$ into $H$. In the context of the variational inequality problem, the characterization of projection (2.1) implies the following:

$$
u \in V I(A, C) \quad \Longleftrightarrow u=P_{C}(u-\lambda A u), \quad \lambda>0 .
$$


It is also known that $H$ satisfies Opial's condition; for any sequence $\left\{x_{n}\right\}$ with $x_{n} \rightarrow x$, the inequality

$$
\liminf _{n \rightarrow \infty}\left\|x_{n}-x\right\|<\liminf _{n \rightarrow \infty}\left\|x_{n}-y\right\|
$$

holds for every $y \in H$ with $y \neq x$.

For solving the generalized mixed equilibrium problem, let us give the following assumptions for the bifunction $F$, the function $\varphi$ and the set $C$ :

(A1) $F(x, x)=0$ for all $x \in C$;

(A2) $F$ is monotone, i.e., $F(x, y)+F(y, x) \leq 0$ for any $x, y \in C$;

(A3) for each $y \in C, x \vdash F(x, y)$ is weakly upper semicontinuous;

(A4) for each $x \in C, y \vdash F(x, y)$ is convex;

(A5) for each $x \in C, y \vdash F(x, y)$ is lower semicontinuous;

(B1) for each $x \in H$ and $r>0$, there exist a bounded subset $D(x) \subset C$ and $y_{x} \in C \cap \operatorname{dom}(\varphi)$ such that for any $z \in C-D_{x}$,

$$
F\left(z, y_{x}\right)+\varphi\left(y_{x}\right)+\left\langle B z, y_{x}-z\right\rangle+\frac{1}{r}\left\langle y_{x}-z, z-x\right\rangle \leq \varphi(z)
$$

(B2) $C$ is a bounded set.

Lemma 2.1 [1] Let $C$ be a nonempty closed convex subset of a Hilbert space $H$. Let $F$ be a bifunction from $C \times C$ to $R$ satisfying (A1)-(A5) and let $\varphi: C \rightarrow R \cup\{+\infty\}$ be a proper lower semicontinuous and convex function. Assume that either (B1) or (B2) holds. For $r>0$ and $x \in H$, define a mapping $T_{r}: H \rightarrow C$ as follows:

$$
T_{r}=\left\{z \in C: F(z, y)+\varphi(y)+\langle B z, y-z\rangle+\frac{1}{r}\langle y-z, z-x\rangle \leq \varphi(z), \forall y \in C\right\}
$$

for all $x \in H$. Then the following conclusions hold:

(1) For each $x \in H, T_{r}(x) \neq \emptyset$;

(2) $T_{r}$ is single-valued;

(3) $T_{r}$ is firmly nonexpansive, i.e., for any $x, y \in H$,

$$
\left\|T_{r}(x)-T_{r}(y)\right\|^{2} \leq\left\langle T_{r}(x)-T_{r}(y), x-y\right\rangle
$$

(4) $\operatorname{Fix}\left(T_{r}(I-r B)\right)=\operatorname{GMEP}(F, \varphi, B)$;

(5) $\operatorname{GMEP}(F, \varphi, B)$ is closed and convex.

Lemma 2.2 [22] For any $x^{*} \in V I(C, A)$, if $A: C \rightarrow H$ is $\alpha$-inverse strongly monotone, then $R_{\lambda}(x)$ is $\left(1-\frac{\lambda}{4 \alpha}\right)$-inverse strongly monotone for any $\lambda \in[0,4 \alpha]$ and

$$
\left\langle x-x^{*}, R_{\lambda}(x)\right| \geq\left(1-\frac{\lambda}{4 \alpha}\right)\left\|R_{\lambda}(x)\right\|^{2},
$$

where $R_{\lambda}(x)=x-P_{C}(x-\lambda A x)$. 
Lemma 2.3 [21] For all $x \in H$ and $\lambda^{\prime} \geq \lambda>0$, it holds that

$$
\left\|R_{\lambda^{\prime}}(x)\right\| \geq\left\|R_{\lambda}(x)\right\|
$$

where $R_{\lambda}(x)=x-P_{C}(x-\lambda A x)$.

Lemma 2.4 [23] Let $\left\{a_{n}\right\}$ and $\left\{b_{n}\right\}$ be two sequences of non-negative numbers, such that $a_{n+1} \leq a_{n}+b_{n}$ for all $n \in N$. If $\sum_{n=1}^{\infty} b_{n}<+\infty$, and if $\left\{a_{n}\right\}$ has a subsequence $\left\{a_{n_{k}}\right\}$ converging to 0 , then $\lim _{n \rightarrow \infty} a_{n}=0$.

Lemma 2.5 [24] Let $H$ be a real Hilbert space, and let $C$ be a nonempty, closed and convex subset of $H$. Let $\left\{x_{n}\right\}$ be a sequence in $H$. Suppose that, for any $x^{*} \in C$,

$$
\left\|x_{n+1}-x^{*}\right\| \leq\left\|x_{n}-x^{*}\right\| \quad(n \in N) .
$$

Then $\lim _{n \rightarrow \infty} P_{C}\left(x_{n}\right)=z$ for some $z \in C$.

\section{Main results}

Theorem 3.1 Let $C$ be a closed and convex subset of a real Hilbert space H. Let $F$ be a bifunction from $C \times C \rightarrow R$ satisfying (A1)-(A5) and $\varphi: C \rightarrow R \cup\{+\infty\}$ be a proper lower semicontinuous and convex function. Let $A$ be an $\alpha$-inverse strongly monotone mapping from $C$ into $H$ and $B$ be an $\beta$-inverse strongly monotone mapping from $C$ into $H$. Let $S$ be a nonexpansive mapping of $C$ into itself, such that $\Omega=\operatorname{Fix}(S) \cap \operatorname{VI}(C, A) \cap \operatorname{GMEP}(F, \varphi, B) \neq \emptyset$. Assume that either (B1) or (B2) holds. Let $\left\{x_{n}\right\},\left\{y_{n}\right\}$ and $\left\{u_{n}\right\}$ be sequences generated by

$$
\left\{\begin{array}{l}
x_{1}=x \in C, \\
F\left(u_{n}, y\right)+\left\langle B x_{n}, y-u_{n}\right\rangle+\varphi(y)-\varphi\left(u_{n}\right)+\frac{1}{r_{n}}\left\langle y-u_{n}, u_{n}-x_{n}\right\rangle \geq 0, \quad \forall y \in C, \\
y_{n}=P_{C}\left(u_{n}-\lambda_{n} A u_{n}\right), \\
x_{n+1}=\alpha_{n} x_{n}+\left(1-\alpha_{n}\right) S\left[\beta_{n} x_{n}+\left(1-\beta_{n}\right) P_{C}\left(y_{n}-\lambda_{n} A y_{n}\right)\right]
\end{array}\right.
$$

for every $n=1,2, \ldots$, where $\left\{\lambda_{n}\right\},\left\{r_{n}\right\},\left\{\alpha_{n}\right\},\left\{\beta_{n}\right\}$ satisfy the following conditions: (i) $0<$ $r_{n}<2 \beta,\left\{\lambda_{n}\right\} \subset[a, b]$ for some $a, b \in(0,2 \alpha)$ and (ii) $\left\{\alpha_{n}\right\} \subset[c, d],\left\{\beta_{n}\right\} \subset[e, f]$ for some $c, d, e, f \in(0,1)$, then $\left\{x_{n}\right\}$ converges strongly to $p^{*} \in \Omega$, where $p^{*}=\lim _{n \rightarrow \infty} P_{\Omega}\left(x_{n}\right)$.

Proof We divide the proof into five steps.

Step 1. We claim that $\left\{x_{n}\right\}$ is bounded and $\lim _{n \rightarrow \infty} R_{a}\left(u_{n}\right)=\lim _{n \rightarrow \infty} R_{\lambda_{n}}\left(u_{n}\right)=0$.

Put

$$
\begin{aligned}
& v_{n}=P_{C}\left(y_{n}-\lambda_{n} A y_{n}\right), \quad w_{n}=\beta_{n} x_{n}+\left(1-\beta_{n}\right) v_{n}, \\
& R_{\lambda_{n}}\left(u_{n}\right)=u_{n}-P_{C}\left(u_{n}-\lambda_{n} A u_{n}\right), \quad R_{\lambda_{n}}\left(y_{n}\right)=y_{n}-P_{C}\left(y_{n}-\lambda_{n} A y_{n}\right)
\end{aligned}
$$

for every $n=1,2, \ldots$. Take any $p \in \Omega$ and let $\left\{T_{r_{n}}\right\}$ be a sequence of mappings defined as in Lemma 2.1, then $p=P_{C}\left(p-\lambda_{n} A p\right)=T_{r_{n}}\left(p-r_{n} B p\right)$. From $u_{n}=T_{r_{n}}\left(x_{n}-r_{n} B x_{n}\right) \in C$, the $\beta$-inverse strongly monotonicity of $B$ and $0<r_{n}<2 \beta$, we have

$$
\begin{aligned}
\left\|u_{n}-p\right\|^{2} & =\left\|T_{r_{n}}\left(x_{n}-r_{n} B x_{n}\right)-T_{r_{n}}\left(p-r_{n} B p\right)\right\|^{2} \\
& \leq\left\|x_{n}-r_{n} B x_{n}-\left(p-r_{n} B p\right)\right\|^{2}
\end{aligned}
$$




$$
\begin{aligned}
& \leq\left\|x_{n}-p\right\|^{2}-2 r_{n}\left\langle x_{n}-p, B x_{n}-B p\right\rangle+r_{n}^{2}\left\|B x_{n}-B p\right\|^{2} \\
& \leq\left\|x_{n}-p\right\|^{2}-2 r_{n} \beta\left\|B x_{n}-B p\right\|^{2}+r_{n}^{2}\left\|B x_{n}-B p\right\|^{2} \\
& =\left\|x_{n}-p\right\|^{2}+r_{n}\left(r_{n}-2 \beta\right)\left\|B x_{n}-B p\right\|^{2} \\
& \leq\left\|x_{n}-p\right\|^{2}
\end{aligned}
$$

and from Lemma 2.2, we have

$$
\begin{aligned}
\left\|y_{n}-p\right\|^{2} & =\left\|u_{n}-R_{\lambda_{n}}\left(u_{n}\right)-p\right\|^{2} \\
& =\left\|u_{n}-p\right\|^{2}-2\left\langle u_{n}-p, R_{\lambda_{n}}\left(u_{n}\right)\right\rangle+\left\|R_{\lambda_{n}}\left(u_{n}\right)\right\|^{2} \\
& \leq\left\|u_{n}-p\right\|^{2}-2\left(1-\frac{\lambda_{n}}{4 \alpha}\right)\left\|R_{\lambda_{n}}\left(u_{n}\right)\right\|^{2}+\left\|R_{\lambda_{n}}\left(u_{n}\right)\right\|^{2} \\
& =\left\|u_{n}-p\right\|^{2}-\left(1-\frac{\lambda_{n}}{2 \alpha}\right)\left\|R_{\lambda_{n}}\left(u_{n}\right)\right\|^{2},
\end{aligned}
$$

which implies from (3.2) that

$$
\left\|y_{n}-p\right\|^{2} \leq\left\|x_{n}-p\right\|^{2}-\left(1-\frac{\lambda_{n}}{2 \alpha}\right)\left\|R_{\lambda_{n}}\left(u_{n}\right)\right\|^{2} .
$$

By the same process as in (3.3), we also have from (3.4) that

$$
\begin{aligned}
\left\|v_{n}-p\right\|^{2} & \leq\left\|y_{n}-p\right\|^{2}-\left(1-\frac{\lambda_{n}}{2 \alpha}\right)\left\|R_{\lambda_{n}}\left(y_{n}\right)\right\|^{2} \\
& \leq\left\|y_{n}-p\right\|^{2}-\left(1-\frac{\lambda_{n}}{2 \alpha}\right)\left\|R_{\lambda_{n}}\left(y_{n}\right)\right\|^{2} \\
& \leq\left\|x_{n}-p\right\|^{2}-\left(1-\frac{\lambda_{n}}{2 \alpha}\right)\left\|R_{\lambda_{n}}\left(u_{n}\right)\right\|^{2}-\left(1-\frac{\lambda_{n}}{2 \alpha}\right)\left\|R_{\lambda_{n}}\left(y_{n}\right)\right\|^{2} .
\end{aligned}
$$

Further, from (3.1) and (3.5), we get

$$
\begin{aligned}
\left\|w_{n}-p\right\|^{2}= & \beta_{n}^{2}\left\|x_{n}-p\right\|^{2}+2 \beta_{n}\left(1-\beta_{n}\right)\left\langle x_{n}-p, v_{n}-p\right\rangle+\left(1-\beta_{n}\right)^{2}\left\|v_{n}-p\right\|^{2} \\
\leq & \beta_{n}^{2}\left\|x_{n}-p\right\|^{2}+2 \beta_{n}\left(1-\beta_{n}\right)\left\|x_{n}-p\right\|^{2}+\left(1-\beta_{n}\right)^{2}\left\|x_{n}-p\right\|^{2} \\
& -\left(1-\beta_{n}\right)^{2}\left(1-\frac{\lambda_{n}}{2 \alpha}\right)\left\|R_{\lambda_{n}}\left(u_{n}\right)\right\|^{2} \\
\leq & \left\|x_{n}-p\right\|^{2}-\left(1-\beta_{n}\right)^{2}\left(1-\frac{\lambda_{n}}{2 \alpha}\right)\left\|R_{\lambda_{n}}\left(u_{n}\right)\right\|^{2} \\
& -\left(1-\beta_{n}\right)^{2}\left(1-\frac{\lambda_{n}}{2 \alpha}\right)\left\|R_{\lambda_{n}}\left(y_{n}\right)\right\|^{2} .
\end{aligned}
$$

Hence, from (3.6), the nonexpansive property of the mapping $S$ and $0<\lambda_{n}<2 \alpha$, we have

$$
\begin{aligned}
\left\|x_{n+1}-p\right\|^{2} & =\alpha_{n}^{2}\left\|x_{n}-p\right\|^{2}+\left(1-\alpha_{n}\right)^{2}\left\|S w_{n}-p\right\|^{2}+2 \alpha_{n}\left(1-\alpha_{n}\right)\left\langle S w_{n}-S p, x_{n}-p\right\rangle \\
& \leq \alpha_{n}^{2}\left\|x_{n}-p\right\|^{2}+\left(1-\alpha_{n}\right)^{2}\left\|w_{n}-p\right\|^{2}+2 \alpha_{n}\left(1-\alpha_{n}\right)\left\|x_{n}-p\right\|^{2} \\
& \leq \alpha_{n}^{2}\left\|x_{n}-p\right\|^{2}+\left(1-\alpha_{n}\right)^{2}\left\|x_{n}-p\right\|^{2}+2 \alpha_{n}\left(1-\alpha_{n}\right)\left\|x_{n}-p\right\|^{2}
\end{aligned}
$$




$$
\begin{aligned}
& -\left(1-\alpha_{n}\right)^{2}\left(1-\beta_{n}\right)^{2}\left(1-\frac{\lambda_{n}}{2 \alpha}\right)\left\|R_{\lambda_{n}}\left(u_{n}\right)\right\|^{2} \\
= & \left\|x_{n}-p\right\|^{2}-\left(1-\alpha_{n}\right)^{2}\left(1-\beta_{n}\right)^{2}\left(1-\frac{\lambda_{n}}{2 \alpha}\right)\left\|R_{\lambda_{n}}\left(u_{n}\right)\right\|^{2} \\
& -\left(1-\alpha_{n}\right)^{2}\left(1-\beta_{n}\right)^{2}\left(1-\frac{\lambda_{n}}{2 \alpha}\right)\left\|R_{\lambda_{n}}\left(y_{n}\right)\right\|^{2} \\
\leq & \left\|x_{n}-p\right\|^{2} .
\end{aligned}
$$

Since the sequence $\left\{\left\|x_{n}-p\right\|\right\}$ is a bounded and nonincreasing sequence, $\lim _{n \rightarrow \infty} \| x_{n}-$ $p \|$ exists. Hence $\left\{x_{n}\right\}$ is bounded. Consequently, the sets $\left\{u_{n}\right\},\left\{v_{n}\right\},\left\{w_{n}\right\},\left\{y_{n}\right\}$ are also bounded. By (3.7), we have

$$
\left(1-\alpha_{n}\right)^{2}\left(1-\beta_{n}\right)^{2}\left(1-\frac{\lambda_{n}}{2 \alpha}\right)\left\|R_{\lambda_{n}}\left(u_{n}\right)\right\|^{2} \leq\left\|x_{n}-p\right\|^{2}-\left\|x_{n+1}-p\right\|^{2} .
$$

From the conditions (i) and (ii), there must exist a constant $M_{1}>0$ such that

$$
M_{1}\left\|R_{\lambda_{n}}\left(u_{n}\right)\right\|^{2} \leq\left(1-\alpha_{n}\right)^{2}\left(1-\beta_{n}\right)^{2}\left(1-\frac{\lambda_{n}}{2 \alpha}\right)\left\|R_{\lambda_{n}}\left(u_{n}\right)\right\|^{2} \leq\left\|x_{n}-p\right\|^{2}-\left\|x_{n+1}-p\right\|^{2},
$$

from which it follows that

$$
M_{1} \sum_{n=1}^{\infty}\left\|R_{\lambda_{n}}\left(u_{n}\right)\right\|^{2} \leq \sum_{n=1}^{\infty}\left[\left\|x_{n}-p\right\|^{2}-\left\|x_{n+1}-p\right\|^{2}\right]=\left\|x_{1}-p\right\|^{2}<\infty
$$

Hence, $\lim _{n \rightarrow \infty} R_{\lambda_{n}}\left(u_{n}\right)=\lim _{n \rightarrow \infty}\left\|R_{\lambda_{n}}\left(u_{n}\right)\right\|=0$. Since $R_{\lambda_{n}}\left(u_{n}\right)=u_{n}-P_{C}\left(u_{n}-\lambda_{n} A u_{n}\right)=$ $u_{n}-y_{n}, \lim _{n \rightarrow \infty}\left\|u_{n}-y_{n}\right\|=0$. Notice that $\lambda_{n} \geq a$, then by Lemma 2.3, $\left\|R_{a}\left(u_{n}\right)\right\| \leq$ $\left\|R_{\lambda_{n}}\left(u_{n}\right)\right\|$. Therefore,

$$
\lim _{n \rightarrow \infty} R_{a}\left(u_{n}\right)=\lim _{n \rightarrow \infty} R_{\lambda_{n}}\left(u_{n}\right)=0 .
$$

By the same way, we also get that

$$
\lim _{n \rightarrow \infty}\left\|R_{\lambda_{n}}\left(y_{n}\right)\right\|=\lim _{n \rightarrow \infty}\left\|y_{n}-v_{n}\right\|=0,
$$

and thus

$$
\lim _{n \rightarrow \infty}\left\|u_{n}-v_{n}\right\|=0 .
$$

Step 2. We show that $\lim _{n \rightarrow \infty}\left\|x_{n}-u_{n}\right\|=\lim _{n \rightarrow \infty}\left\|S x_{n}-x_{n}\right\|=0$.

Indeed, for any $p \in \Omega$, it follows from (3.1) and (3.5) that

$$
\begin{aligned}
\left\|w_{n}-p\right\|^{2} & =\beta_{n}\left\|x_{n}-p\right\|^{2}+\left(1-\beta_{n}\right)\left\|v_{n}-p\right\|^{2}-\beta_{n}\left(1-\beta_{n}\right)\left\|x_{n}-v_{n}\right\|^{2} \\
& \leq\left\|x_{n}-p\right\|^{2}-\beta_{n}\left(1-\beta_{n}\right)\left\|x_{n}-v_{n}\right\|^{2},
\end{aligned}
$$

which implies that

$$
\begin{aligned}
\left\|x_{n+1}-p\right\|^{2} & =\alpha_{n}\left\|x_{n}-p\right\|^{2}+\left(1-\alpha_{n}\right)\left\|w_{n}-p\right\|^{2}-\alpha_{n}\left(1-\alpha_{n}\right)\left\|S w_{n}-x_{n}\right\|^{2} \\
& \leq\left\|x_{n}-p\right\|^{2}-\alpha_{n}\left(1-\alpha_{n}\right)\left\|S w_{n}-x_{n}\right\|^{2}-\beta_{n}\left(1-\beta_{n}\right)\left\|x_{n}-v_{n}\right\|^{2} .
\end{aligned}
$$


Thus, it follows from (3.10) that

$$
\alpha_{n}\left(1-\alpha_{n}\right)\left\|S w_{n}-x_{n}\right\|^{2} \leq\left\|x_{n}-p\right\|^{2}-\left\|x_{n+1}-p\right\|^{2} .
$$

From the condition (ii), there exists a constant $M_{2}>0$ such that

$$
M_{2}\left\|S w_{n}-x_{n}\right\|^{2} \leq \alpha_{n}\left(1-\alpha_{n}\right)\left\|S w_{n}-x_{n}\right\|^{2} \leq\left\|x_{n}-p\right\|^{2}-\left\|x_{n+1}-p\right\|^{2},
$$

from which it follows that

$$
M_{2} \sum_{n=1}^{\infty}\left\|S w_{n}-x_{n}\right\|^{2} \leq \sum_{n=1}^{\infty}\left[\left\|x_{n}-p\right\|^{2}-\left\|x_{n+1}-p\right\|^{2}\right]=\left\|x_{1}-p\right\|^{2}<\infty
$$

Hence

$$
\lim _{n \rightarrow \infty}\left\|S w_{n}-x_{n}\right\|=0
$$

From (3.10), we also get that

$$
\beta_{n}\left(1-\beta_{n}\right)\left\|x_{n}-v_{n}\right\|^{2} \leq\left\|x_{n}-p\right\|^{2}-\left\|x_{n+1}-p\right\|^{2} .
$$

By the same way, we obtain that

$$
\lim _{n \rightarrow \infty}\left\|x_{n}-v_{n}\right\|=0,
$$

which combining (3.9) implies that

$$
\lim _{n \rightarrow \infty}\left\|x_{n}-u_{n}\right\|=0
$$

Since

$$
\begin{aligned}
\left\|S x_{n}-x_{n}\right\| & \leq\left\|S x_{n}-S v_{n}\right\|+\left\|S v_{n}-S w_{n}\right\|+\left\|S w_{n}-x_{n}\right\| \\
& \leq\left\|x_{n}-v_{n}\right\|+\left\|v_{n}-w_{n}\right\|+\left\|S w_{n}-x_{n}\right\| \\
& \leq\left\|x_{n}-v_{n}\right\|+\beta_{n}\left\|x_{n}-v_{n}\right\|+\left\|S w_{n}-x_{n}\right\|,
\end{aligned}
$$

which implies from (3.11), (3.12) that

$$
\lim _{n \rightarrow \infty}\left\|S x_{n}-x_{n}\right\|=0 .
$$

Further, it follows from (3.1) and (3.11) that

$$
\left\|x_{n+1}-x_{n}\right\|=\left(1-\alpha_{n}\right)\left\|S w_{n}-x_{n}\right\| \leq(1-c)\left\|S w_{n}-x_{n}\right\| \rightarrow 0 \quad(n \rightarrow \infty) .
$$

Step 3. We claim that $\left\{x_{n}\right\}$ must have a convergent subsequence $\left\{x_{n_{k}}\right\}$ such that $\lim _{k \rightarrow \infty} x_{n_{k}}=p^{*}$ for some $p^{*} \in C$. Moreover, $p^{*} \in \Omega=\operatorname{Fix}(S) \cap V I(C, A) \cap \operatorname{GMEP}(F, \varphi, B)$. 
Since $\left\{x_{n}\right\}$ is a bounded sequence generated by Algorithm (3.1), then $\left\{x_{n}\right\}$ must have a weakly convergent subsequence $\left\{x_{n_{k}}\right\}$ such that $x_{n_{k}} \rightarrow p^{*}(k \rightarrow \infty)$, which implies from (3.11) and (3.13) that $S w_{n_{k}} \rightarrow p^{*}(k \rightarrow \infty)$ and $u_{n_{k}} \rightarrow p^{*}(k \rightarrow \infty)$. Next we will show that $p^{*} \in \Omega=\operatorname{Fix}(S) \cap V I(C, A) \cap \operatorname{GMEP}(F, \varphi, B)$.

Since $A$ is inverse strongly monotone with the positive constant $\alpha>0$, so $A$ is $\frac{1}{\alpha}$-Lipschitz continuous. Indeed, it yields that $\|A x-A y\| \leq \frac{1}{\alpha}\|x-y\|$ from the definition of the inverse strongly monotonicity of $A$, such that

$$
\alpha\|A x-A y\|^{2} \leq\langle A x-A y, x-y\rangle \leq\|A x-A y\|\|x-y\| .
$$

From the $\frac{1}{\alpha}$-Lipschitz continuity of $A$ and the continuity of $P_{C}$, it follows that $R_{a}(x)=$ $x-P_{C}[x-a A x]$ is also continuous. Notice that $\rho_{n} \geq a$, then by Lemma 2.3, $\left\|R_{x}\left(x_{n}\right)\right\| \leq$ $\left\|R_{\rho_{n}}\left(x_{n}\right)\right\|$. Then from Step 1 ,

$$
\lim _{k \rightarrow \infty}\left\|R_{x}\left(x_{n_{k}}\right)\right\|=\lim _{n \rightarrow \infty}\left\|R_{\rho_{n}}\left(x_{n_{k}}\right)\right\|=0 .
$$

Therefore from the continuity of $R_{a}(x)$,

$$
R_{a}\left(p^{*}\right)=\lim _{n \rightarrow \infty} R_{a}\left(x_{n_{k}}\right)=0 .
$$

This shows that $p^{*}$ is a solution of the variational inequality (1.6), that is $p^{*} \in V I(C, A)$. From (3.12), $\lim _{n \rightarrow \infty}\left\|x_{n_{k}}-p^{*}\right\|=0$ and the property of the nonexpansive mapping $S$, it follows that $p^{*}=S p^{*}$, that is $p^{*} \in \operatorname{Fix}(S)$. Finally, by the same argument as in the proof of [7, Theorem 3.1], we prove that $p^{*} \in \operatorname{GMEP}(F, \varphi, B)$. Thus $p^{*} \in \Omega=\operatorname{Fix}(S) \cap V I(C, A) \cap$ $\operatorname{GMEP}(F, \varphi, B)$.

Next, we will prove that $x_{n_{k}} \rightarrow p^{*}(k \rightarrow \infty)$.

From (3.1), (3.6) and (3.7) we can calculate

$$
\begin{aligned}
\left\|x_{n+1}-p^{*}\right\|^{2}= & \left\langle\alpha_{n} x_{n}+\left(1-\alpha_{n}\right) S w_{n}-p^{*}, x_{n+1}-p^{*}\right\rangle \\
= & \alpha_{n}\left(x_{n}-p^{*}, x_{n+1}-p^{*}\right\rangle+\left(1-\alpha_{n}\right)\left\langle S w_{n}-p^{*}, x_{n+1}-p^{*}\right\rangle \\
\leq & \alpha_{n}\left\|x_{n}-p^{*}\right\|^{2}+\left(1-\alpha_{n}\right)\left\langle S w_{n}-p^{*}, x_{n+1}-p^{*}\right\rangle \\
\leq & \alpha_{n}\left\|x_{n}-p^{*}\right\|^{2}+\left(1-\alpha_{n}\right)\left\langle S w_{n}-p^{*}, x_{n+1}-x_{n}\right\rangle \\
& +\left(1-\alpha_{n}\right)\left\langle S w_{n}-p^{*}, x_{n}-p^{*}\right\rangle \\
\leq & \alpha_{n}\left\|x_{n}-p^{*}\right\|^{2}+\left(1-\alpha_{n}\right)\left\|x_{n}-p^{*}\right\|^{2}+\left(1-\alpha_{n}\right)\left\langle S w_{n}-p^{*}, x_{n+1}-x_{n}\right\rangle \\
= & \left\|x_{n}-p^{*}\right\|^{2}+\left(1-\alpha_{n}\right)\left\langle S w_{n}-p^{*}, x_{n+1}-x_{n}\right\rangle,
\end{aligned}
$$

which implies

$$
\begin{aligned}
\left\|x_{n+1}-p^{*}\right\|^{2}-\left\|x_{n}-p^{*}\right\|^{2} & \leq\left(1-\alpha_{n}\right)\left\langle S w_{n}-p^{*}, x_{n+1}-x_{n}\right\rangle \\
& \leq(1-c)\left\langle S w_{n}-p^{*}, x_{n+1}-x_{n}\right\rangle .
\end{aligned}
$$

From $S w_{n_{k}} \rightarrow p^{*}$ and $x_{n_{k+1}}-x_{n_{k}} \rightarrow 0$ as $k \rightarrow \infty$, it follows from (3.16) that

$$
\left\|x_{n_{k+1}}-p^{*}\right\| \rightarrow\left\|x_{n_{k}}-p^{*}\right\| \quad(k \rightarrow \infty) .
$$

Using the Kadec-Klee property of $H$, we obtain that $\lim _{k \rightarrow \infty} x_{n_{k}}=p^{*}$. 
Step 4. We claim that the sequence $\left\{x_{n}\right\}$ generated by Algorithm (3.1) converges strongly to $p^{*} \in \Omega=\operatorname{Fix}(S) \cap V I(C, A) \cap \operatorname{GMEP}(F, \varphi, B)$.

In fact, from the result of Step 3, $p^{*} \in \Omega$. Let $p=p^{*}$ in (3.7). Consequently, $\left\|x_{n+1}-p^{*}\right\| \leq$ $\left\|x_{n}-p^{*}\right\|$. Meanwhile, $\lim _{k \rightarrow \infty}\left\|x_{n_{k}}-p^{*}\right\|=0$ from Step 3. Then from Lemma 2.4, we have $\lim _{n \rightarrow \infty}\left\|x_{n}-p^{*}\right\|=0$. Therefore, $\lim _{n \rightarrow \infty} x_{n}=p^{*}$.

Step 5. We claim that $p^{*}=\lim _{n \rightarrow \infty} P_{\Omega} x_{n}$.

From (2.1), we have

$$
\left\langle x_{n}-P_{\Omega} x_{n}, p^{*}-P_{\Omega} x_{n}\right\rangle \leq 0 .
$$

By (3.7) and Lemma 2.5, $\lim _{n \rightarrow \infty} P_{\Omega} x_{n}=q^{*}$ for some $q^{*} \in \Omega$. Then in (3.13), let $n \rightarrow \infty$, since $\lim _{n \rightarrow \infty} x_{n}=p^{*}$ by Step 4 , we have

$$
\left\langle p^{*}-q^{*}, p^{*}-q^{*}\right\rangle \leq 0
$$

and, consequently, we have $p^{*}=q^{*}$. Hence, $p^{*}=\lim _{n \rightarrow \infty} P_{\Omega} x_{n}$.

This completes the proof of Theorem 3.1.

The following theorems can be obtained from Theorem 3.1 immediately.

Theorem 3.2 Let $C, H, S$ be as in Theorem 3.1. Assume that $\Omega=\operatorname{Fix}(S) \cap V I(C, A) \neq \emptyset$, let $\left\{x_{n}\right\},\left\{y_{n}\right\}$ be sequences generated by

$$
\left\{\begin{array}{l}
x_{1}=x \in C, \\
y_{n}=P_{C}\left(x_{n}-\lambda_{n} A x_{n}\right), \\
x_{n+1}=\alpha_{n} x_{n}+\left(1-\alpha_{n}\right) S\left[\beta_{n} x_{n}+\left(1-\beta_{n}\right) P_{C}\left(y_{n}-\lambda_{n} A y_{n}\right)\right]
\end{array}\right.
$$

for every $n=1,2, \ldots$, where $\left\{\lambda_{n}\right\},\left\{\alpha_{n}\right\},\left\{\beta_{n}\right\}$ satisfy the following conditions: (i) $\left\{\lambda_{n}\right\} \subset[a, b]$ for some $a, b \in(0,2 \alpha)$ and (ii) $\left\{\alpha_{n}\right\} \subset[c, d],\left\{\beta_{n}\right\} \subset[e, f]$ for some $c, d, e, f \in(0,1)$, then $\left\{x_{n}\right\}$ converges strongly to $p^{*} \in \Omega$, where $p^{*}=\lim _{n \rightarrow \infty} P_{\Omega}\left(x_{n}\right)$.

Proof Putting $B=F=\varphi=0, r_{n}=1$ in Theorem 3.1, the conclusion of Theorem 3.2 can be obtained from Theorem 3.1.

Remark 3.1 The main result of Nadezhkina and Takahashi [14] is a special case of our Theorem 3.2. Indeed, if we take $\beta_{n}=0$ in Theorem 3.2, then we obtain the result of [14].

Theorem 3.3 Let $C, H, F, A, B, S$ be as in Theorem 3.1. Assume $\Omega=\operatorname{Fix}(S) \cap V I(C, A) \cap$ $\operatorname{GEP}(F, B) \neq \emptyset ;$ let $\left\{x_{n}\right\},\left\{y_{n}\right\}$ and $\left\{u_{n}\right\}$ be sequences generated by

$$
\left\{\begin{array}{l}
x_{1}=x \in C, \\
F\left(u_{n}, y\right)+\left\langle B x_{n}, y-u_{n}\right\rangle+\frac{1}{r_{n}}\left\langle y-u_{n}, u_{n}-x_{n}\right\rangle \geq 0, \quad \forall y \in C, \\
y_{n}=P_{C}\left(u_{n}-\lambda_{n} A u_{n}\right), \\
x_{n+1}=\alpha_{n} x_{n}+\left(1-\alpha_{n}\right) S\left[\beta_{n} x_{n}+\left(1-\beta_{n}\right) P_{C}\left(y_{n}-\lambda_{n} A y_{n}\right)\right]
\end{array}\right.
$$

for every $n=1,2, \ldots$, where $\left\{\lambda_{n}\right\},\left\{r_{n}\right\},\left\{\alpha_{n}\right\},\left\{\beta_{n}\right\}$ satisfy conditions (i) and (ii) as in Theorem 3.1, then $\left\{x_{n}\right\}$ converges strongly to $p^{*} \in \Omega$, where $p^{*}=\lim _{n \rightarrow \infty} P_{\Omega}\left(x_{n}\right)$. 
Proof Putting $\varphi=0$ in Theorem 3.1, the conclusion of Theorem 3.3 is obtained.

Remark 3.2 Theorem 3.3 can be viewed as an improvement of Theorem 3.1 of Inchan [25] because of removing the iterative step $C_{n}$ in the algorithm of Theorem 3.1 of [25].

Theorem 3.4 Let $C, H, F, A, S$ be as in Theorem 3.1. Assume that $\Omega=\operatorname{Fix}(S) \cap V I(C, A) \cap$ $E P(F) \neq \emptyset ;$ let $\left\{x_{n}\right\}$ and $\left\{u_{n}\right\}$ be sequences generated by

$$
\left\{\begin{array}{l}
x_{1}=x \in C, \\
F\left(u_{n}, y\right)+\frac{1}{r_{n}}\left\langle y-u_{n}, u_{n}-x_{n}\right\rangle \geq 0, \quad \forall y \in C, \\
y_{n}=P_{C}\left(u_{n}-\lambda_{n} A u_{n}\right), \\
x_{n+1}=\alpha_{n} x_{n}+\left(1-\alpha_{n}\right) S P_{C}\left(y_{n}-\lambda_{n} A y_{n}\right)
\end{array}\right.
$$

for every $n=1,2, \ldots$, where $\left\{\lambda_{n}\right\},\left\{r_{n}\right\},\left\{\alpha_{n}\right\}$ satisfy the following conditions: $0<r_{n}<2 \beta$, $\left\{\lambda_{n}\right\} \subset[a, b]$ for some $a, b \in(0,2 \alpha),\left\{\alpha_{n}\right\} \subset[c, d]$ for some $c, d \in(0,1)$, then $\left\{x_{n}\right\}$ converges strongly to $p^{*} \in \Omega$, where $p^{*}=\lim _{n \rightarrow \infty} P_{\Omega}\left(x_{n}\right)$.

Proof Taking $B=\varphi=0, \beta_{n}=0$ in Theorem 3.1, the conclusion of Theorem 3.4 is obtained.

Remark 3.3 Theorem 3.4 is the strong convergence result of Theorem 3.1 of Jaiboon, Kumam and Humphries [26].

\section{Competing interests}

The authors declare that they have no competing interests.

\section{Authors' contributions}

$S L$ and $L L$ carried out the proof of convergence of the theorems. LC, XH and XY carried out the check of the manuscript. All authors read and approved the final manuscript.

\section{Author details}

'College of Mathematics and Information Technology, Hebei Normal University of Science and Technology, Qinhuangdao, 066004, China. ${ }^{2}$ Institute of Mathematics and Systems Science, Hebei Normal University of Science and Technology, Qinhuangdao, 066004, China. ${ }^{3}$ Hebei Business and Trade School, Shijiazhuang, 050000, China.

\section{Acknowledgements}

The authors are very grateful to the referees for their careful reading, comments and suggestions, which improved the presentation of this article. The first author was supported by the Natural Science Foundational Committee of Qinhuangdao city (201101 A453) and Hebei Normal University of Science and Technology (ZDJS 2009 and CXTD2010-05). The fifth author was supported by the Natural Science Foundational Committee of Qinhuangdao city (2012025A034).

Received: 18 September 2012 Accepted: 23 July 2013 Published: 31 October 2013

\section{References}

1. Peng, JW, Yao, JC: A new hybrid-extragradient method for generalized mixed equilibrium problems and fixed point problems and variational inequality problems. Taiwan. J. Math. 12(6), 1401-1432 (2008)

2. Ceng, LC, Yao, JC: A hybrid iterative scheme for mixed equilibrium problems and fixed point problems. J. Comput. Appl. Math. 214, 186-201 (2008)

3. Peng, JW, Yao, JC: Strong convergence theorems of iterative scheme based on the extragradient method for mixed equilibrium problems and fixed point problems. Math. Comput. Model. 49, 1816-1828 (2009)

4. Peng, JW, Yao, JC: An iterative algorithm combining viscosity method with parallel method for a generalized equilibrium problem and strict pseudocontractions. Fixed Point Theory Appl. 2009, Article ID 794178 (2009)

5. Takahashi, S, Takahashi, W: Strong convergence theorem for a generalized equilibrium problem and a nonexpansive mapping in a Hilbert space. Nonlinear Anal. 69, 1025-1033 (2008)

6. Flam, SD, Antipin, AS: Equilibrium programming using proximal-like algorithms. Math. Program. 78, $29-41$ (1997)

7. Blum, E, Oettli, W: From optimization and variational inequalities to equilibrium problems. Math. Stud. 63, 123-145 (1994) 
8. Korpelevich, GM: The extragradient method for finding saddle points and other problems. Matecon 12, 747-756 (1976)

9. He, BS, Yang, ZH, Yuan, XM: An approximate proximal-extragradient type method for monotone variational inequalities. J. Math. Anal. Appl. 300, 362-374 (2004)

10. Gárciga Otero, R, luzem, A: Proximal methods with penalization effects in Banach spaces. Numer. Funct. Anal. Optim. 25, 69-91 (2004)

11. Solodov, MV, Svaiter, BF: An inexact hybrid generalized proximal point algorithm and some new results on the theory of Bregman functions. Math. Oper. Res. 25, 214-230 (2000)

12. Solodov, MV: Convergence rate analysis of interactive algorithms for solving variational inequality problem. Math. Program. 96, 513-528 (2003)

13. Zeng, LC, Yao, JC: Strong convergence theorem by an extragradient method for fixed point problems and variational inequality problems. Taiwan. J. Math. 10, 1293-1303 (2006)

14. Nadezhkina, N, Takahashi, W: Weak convergence theorem by an extragradient method for nonexpansive mappings and monotone mappings. J. Optim. Theory Appl. 128, 191-201 (2006)

15. Yao, Y, Yao, JC: On modified iterative method for nonexpansive mappings and monotone mappings. Appl. Math. Comput. 186, 1551-1558 (2007)

16. Plubtieng, S, Punpaeng, R: A new iterative method for equilibrium problems and fixed point problems of nonexpansive mappings and monotone mappings. Appl. Math. Comput. 197, 548-558 (2008)

17. Takahashi, W, Toyoda, M: Weak convergence theorems for nonexpansive mappings and monotone mappings. J. Optim. Theory Appl. 118, 417-428 (2003)

18. Zeng, LC, Yao, JC: Strong convergence theorem by an extragradient method for fixed point problems and variational inequality problems. Taiwan. J. Math. 10, 1293-1303 (2006)

19. Nadezhkina, N, Takahashi, W: Weak convergence theorem by an extragradient method for nonexpansive mappings. J. Optim. Theory Appl. 128, 191-201 (2006)

20. Noor, MA, Rassias, TM: Projection methods for monotone variational inequalities. J. Math. Anal. Appl. 237, 405-412 (1999)

21. Huang, ZY, Noor, MA, Al-Said, E: On an open question of Takahashi for nonexpansive mappings and inverse strongly monotone mappings. J. Optim. Theory Appl. 147, 194-204 (2010)

22. Bnouhachem, A, Noor, MA: A new iterative method for variational inequalities. Appl. Math. Comput. 182, 1673-1682 (2006)

23. Liu, QH: Convergence theorems of the sequence of iterates for asymptotically demicontractive and hemicontractive mappings. Nonlinear Anal. 26, 1835-1842 (1996)

24. Takahashi, W, Toyoda, M: Weak convergence theorems for nonexpansive mappings and monotone mappings. J. Optim. Theory Appl. 118, 417-428 (2003)

25. Inchan, I: Hybrid extragradient method for general equilibrium problems and fixed point problems in Hilbert space. Nonlinear Anal. Hybrid Syst. 5, 467-478 (2011)

26. Jaiboon, C, Kumam, P, Humphries, UW: Weak convergence theorem by an extragradient method for variational inequality, equilibrium and fixed point problems. Bull. Malays. Math. Sci. Soc. 32, 173-185 (2009)

doi:10.1186/1687-1812-2013-240

Cite this article as: Li et al. Hybrid extragradient method for generalized mixed equilibrium problems and fixed point problems in Hilbert space. Fixed Point Theory and Applications 2013 2013:240.

\section{Submit your manuscript to a SpringerOpen ${ }^{\circ}$ journal and benefit from:}

- Convenient online submission

Rigorous peer review

- Immediate publication on acceptance

- Open access: articles freely available online

- High visibility within the field

- Retaining the copyright to your article 